\section{Artemisia annua: Uma Solução Terapêutica Contra a COVID-19}

Atualmente, não existe um tratamento específico contra o coronavírus SARS-CoV-2. A esperança recai naturalmente em vacinas que possibilitem a obtenção da imunidade de grupo. Contudo, a longo prazo, talvez seja necessário procurar alternativas terapêuticas. A partir deste pressuposto, vários tratamentos à base de extratos fitoquímicos usados na Medicina Tradicional Chinesa foram explorados para tratar infeções por coronavírus. Estudos iniciais mostraram que o extrato alcoólico de absinto doce (Artemisia annua) foi o segundo medicamento fitoterapêutico mais potente usado no surto de SARS-CoV de 2005, cujas propriedades biológicas se devem principalmente à artemisinina.

A artemisinina é uma lactona sesquiterpénica descoberta pela farmacologista chinesa Tu Youyou, permitindo-Ihe arrecadar em 2015 o Prémio Nobel de Fisiologia ou Medicina. Em termos químicos, a particularidade estrutural da artemisinina que lhe confere a respetiva atividade é o endoperóxido, incorporada no anel de 1,2,4-trioxano, que está envolvida no mecanismo de ação, ainda não totalmente elucidado. No entanto, os estudos realizados indicam que o anel de endoperóxido sofre clivagem oxidativa na presença de ferro(II) presente em hemeproteínas, originando radicais livres altamente reativos que danificam proteínas e material genético do parasita, resultando na respetiva morte, daí o seu uso no tratamento da malária.

Investigadores do Instituto Max Planck de Coloides e Interfaces, de Potsdam, Alemanha, avaliaram o potencial dos extratos vegetais de Artemisia annua e derivados de artemisinina contra o novo coronavírus SARS-CoV-2 e descobriram que os extratos fitoquímicos

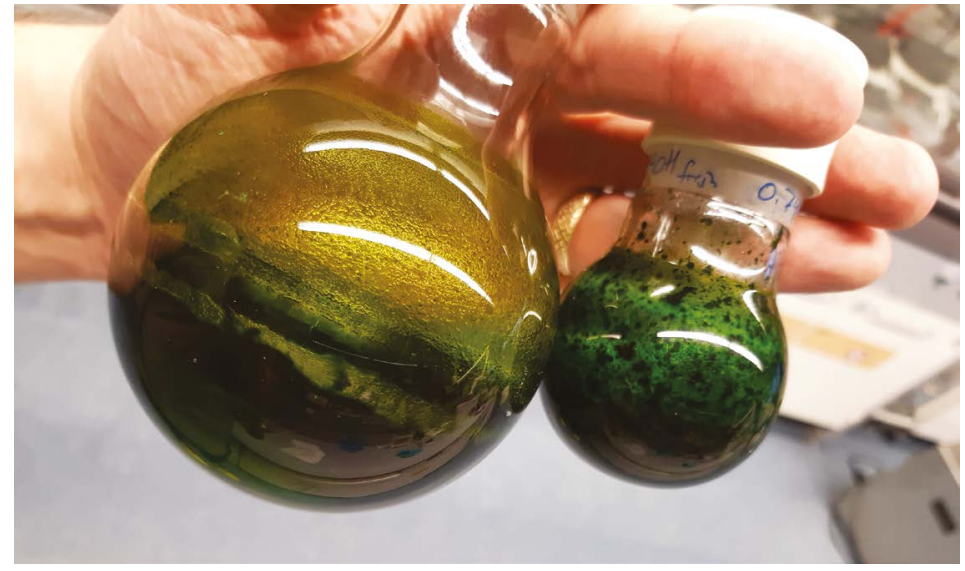

Crédito: Kerry Gilmore

evidenciavam atividade antiviral após serem extraídos com etanol puro ou água destilada, e que a atividade aumenta consideravelmente quando os extratos obtidos são combinados com alcaloides, sobretudo com a cafeína. Apesar dos resultados relativos aos ensaios in vitro serem promissores, a próxima etapa passará por testar a atividade dos extratos vegetais de Artemisia annua no tratamento da COVID-19 em humanos, com o uso de chás e cafés, no centro médico académico da Universidade de Kentucky, de forma a determinar se a Artemisia annua pode ser efetivamente usada contra o SARS-CoV-2.

\section{José R. A. Coelho}

pg42590@alunos.uminho.pt

\section{Fontes}

Artemisia annua to be tested against Coronavirus, mpg.de/14663263/artemisiaannua-corona-virus (acedido em 20/02/2021).

K. Gilmore, Y. Zhou, S. Ramirez, L. V. Pham, U. Fahnøe, S. Feng, A. Offersgaard, J. Trimpert, J. Bukh, K. Osterrieder, J. M. Gottwein, P. H. Seeberger, BioRXiv. DOI: 10.1101/2020.10.05.326637.

\section{Síntese de}

$\mathrm{N}$-Alquilanilinas

Através de

Aminação C-H

Aromática com Ferro
As aminas aromáticas são particularmente importantes devido à sua utilização em produtos farmacêuticos, agroquímicos, catalisadores ou corantes. A preparação destes compostos através de reações de aminação de arenos obriga à construção de ligações $\mathrm{C}\left(s p^{2}\right)-\mathrm{N}$. Geralmente, as abordagens tradicionais para a aminação de arenos envolvem vários passos sintéticos e condições experimentais bastante exigentes. 
Eric Falk e colaboradores, do Instituto Federal de Tecnologia de Zurique, na Suíça, desenvolveram uma metodologia mais simples para a aminação de arenos, usando sais de ferro(II) como catalisadores e derivados de hidroxilamina como agentes de aminação altamente eletrofílicos, possibilitando a síntese de $\mathrm{N}$-metilanilinas e tetra-hidroquinolinas. Esta equipa de investigação estabeleceu que o catalisador $\left(\mathrm{FeSO}_{4} \cdot 7 \mathrm{H}_{2} \mathrm{O}\right)$ e o reagente de aminação $\left[\mathrm{NsO}-\mathrm{NH}_{2}-\mathrm{CH}_{3}\right]+$ OTf ( Ns = nosilo, OTf = triflato), utilizando 1,1,1,3,3,3-hexafluoroisopropanol (HFIP) como solvente, permitem a eficaz $\mathrm{N}$-metilaminação do benzeno. A reação pode ser realizada ao ar, a $40^{\circ} \mathrm{C}$, pelo que é operacionalmente simples, não requerendo equipamento especializado. Usando esta abordagem foi possível transformar arenos neutros e ricos em eletrões nos correspondentes produtos com o grupo $\mathrm{N}$-metilamina com rendimentos moderados a elevados (44-89\%). Além disso, as condições de reação permitem a preparação de tetra-hidroquinolinas através da reação intramolecular de arenos com um substituinte propílico, funcionalizado com o grupo N(OTs)Boc (Ts = tosilo, Boc = terc-butiloxicarbonilo), na presença de ácido trifluoroacético para promover in situ a desproteção do material de partida. Os derivados de tetra-hidroquinolina foram obtidos com rendimentos razoáveis (34-56\%).

0 processo descrito por Eric Falk e colaboradores permite a síntese de $\mathrm{N}$-metilanilinas e tetra-hidroquinolinas a partir de arenos simples, promovidas por sais de ferro(II), sem necessidade de controlo de exposição ao oxigénio do ar ou à humidade e facilmente realizadas em condições suaves.

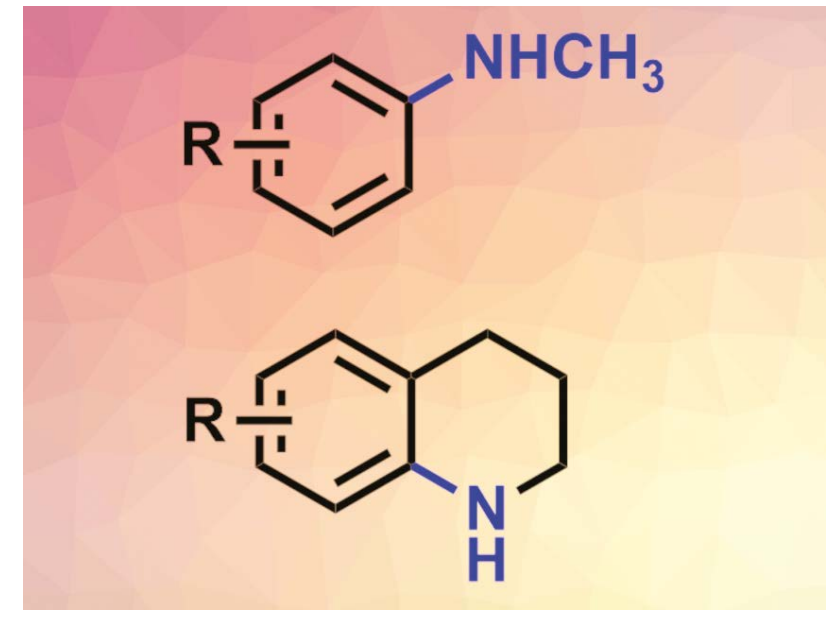

Crédito: ChemistryViews

$>$

José R. A. Coelho

pg42590@alunos.uminho.pt

\section{Fontes}

Iron-Catalyzed Synthesis of N-Alkyl Anilines, chemistryviews.org/details/ news/11288171/Iron-Catalyzed_Synthesis_of_N Alkyl_Anilines (acedido em 22/02/2021).

E. Falk, V. C. M. Gasser, B. Morandi, Org. Lett. 2021, 23, 1422-1426. DOI: 10.1021/ acs.orglett.1c00099.

\section{Espectroscopia de RMN Usada para Certificar Café}

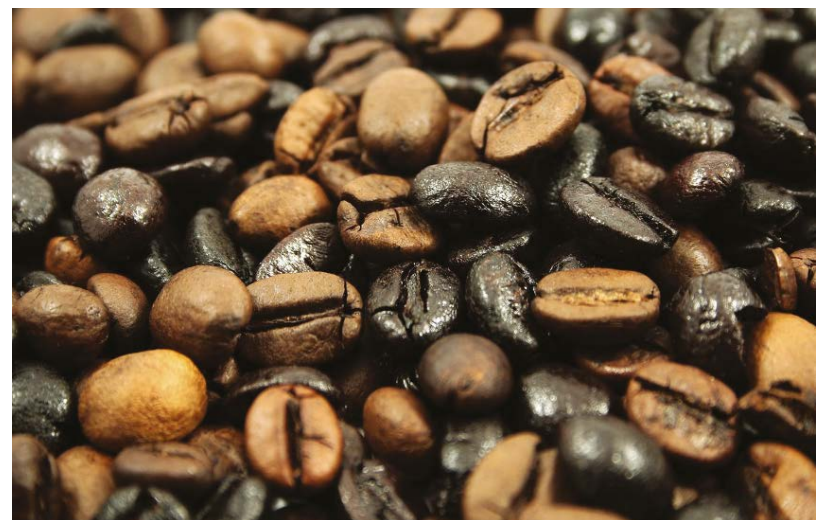

Crédito: ChemistryViews
0 café é uma das bebidas mais consumidas no mundo. Entre cerca de 500 espécies de café, existem duas variedades com maior importância comercial: a Coffea arabica e a Coffea canephora var. Robusta, conhecidas como cafés arábica e robusta, respetivamente. 0 café arábica é considerado, geralmente, de qualidade superior em comparação com o robusta, tendo um preço superior. A adulteração do café arábica com o robusta, mais barato, pode ser difícil de detetar uma vez que os grãos são torrados e moídos. A deteção dessas adulterações é importante de modo a garantir a proteção do consumidor e a capacidade da indústria alimentar e de bebidas para obter produtos de alta qualidade. Assim, há necessidade de desenvolver soluções analíticas inovadoras que permitam garantir a autenticidade e qualidade das matérias-primas e de produtos alimentares.

Fabrice Berrué (Centro de Pesquisa de Desenvolvimento de Recursos Aquáticos e Culturais, Conselho 